\section{ZEW}

Zentrum für Europäische Wirtschaftsforschung $\mathrm{GmbH}$

Centre for European Economic Research

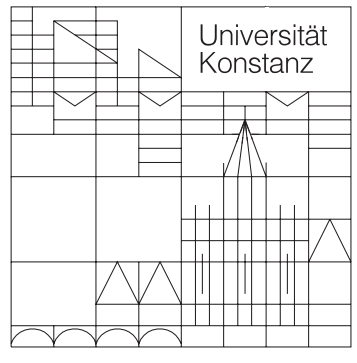

Rechts-, Wirtschafts- und Verwaltungswissenschaftliche Sektion Fachbereich

Wirtschaftswissenschaften

Diskussionspapiere der DFG-

Forschergruppe (Nr.: 3468269275):

Heterogene Arbeit: Positive und Normative Aspekte der Qualifikationsstruktur der Arbeit

David B. Audretsch, Erik E. Lehmann, Susanne Warning

University Spillovers and New Firm Location

Mai 2004 
Diskussionspapier der Forschergruppe (Nr.: 3468269275) "Heterogene Arbeit: Positive und Normative Aspekte der Qualifikationsstruktur der Arbeit"

Nr. 04/13, Mai 2004

\section{University Spillovers and New Firm Location}

\section{David B. Audretsch}

Institute for Development Strategies

1315 E. 10th Street

SPEA 201

Bloomington, IN 47405

USA

mail:_daudrets@indiana.edu

\section{Erik E. Lehmann}

Fach D 144

78457 Konstanz

Germany

mail : erik.lehmann@uni-konstanz.de
Susanne Warning

\author{
Fach D 144 \\ 78457 Konstanz \\ Germany \\ mail : susanne.warning@uni-konstanz.de
}

\section{Zusammenfassung:}

This paper examines the impact of locational choice as a firm strategy to access knowledge spillovers from universities. Based on a large data set of young high-technology start-ups publicly listed in Germany, this study tests the propositions that geographic proximity to the university is shaped by different spillover mechanisms -- research and human capital -- and by different types of knowledge spillover -- natural sciences and social sciences. The results suggest that spillover mechanisms as well as spillover types are heterogeneous. In particular, the evidence suggests that new knowledge and technological-based firms have a high propensity to locate close to universities, presumably in order to access knowledge spillovers. However, the exact role that geographic proximity plays is shaped by the two factors examined in this paper -the particular knowledge context, and the specific type of spillover mechanism. 


\title{
University Spillovers and New Firm Location
}

\author{
David B. Audretsch ${ }^{*}$, Indiana University, Bloomington, CEPR, and Max Planck \\ Institute for Research into Economic Systems \\ Erik E. Lehmann, University of Konstanz \\ Susanne Warning, University of Konstanz
}

\begin{abstract}
This paper examines the impact of locational choice as a firm strategy to access knowledge spillovers from universities. Based on a large data set of young high-technology start-ups publicly listed in Germany, this study tests the propositions that geographic proximity to the university is shaped by different spillover mechanisms -- research and human capital -- and by different types of knowledge spillover -- natural sciences and social sciences. The results suggest that spillover mechanisms as well as spillover types are heterogeneous. In particular, the evidence suggests that new knowledge and technological-based firms have a high propensity to locate close to universities, presumably in order to access knowledge spillovers. However, the exact role that geographic proximity plays is shaped by the two factors examined in this paper -the particular knowledge context, and the specific type of spillover mechanism.
\end{abstract}

Keywords: university spillover; new firm location; spillover mechanisms

JEL: M13, L20, R30

\footnotetext{
* David B. Audretsch, Institute for Development Strategies, Indiana University, SPEA, Suite 201, Bloomington, IN 47405-2100, email: daudrets@indiana.edu, Phone: (+1) 812855 6766, Fax.: (+1) 812855-0184
} 


\section{$1 \quad$ Introduction}

The assets that really count are those accountants can't count

(T. A. Stewart 1995, in Fortune 137 (7), p. 157).

In proposing a new theory of economic geography (Krugman, 1991, p. 5) asks, "What is the most striking feature of the geography of economic activity? The short answer is surely concentration [...] production [...] is remarkably concentrated in space.” As for other fields of economics, the impact of geography has not escaped the attention of scholars of entrepreneurship. A recent wave of studies has focused on the locational decision of new-firm startups. Indeed, an important finding of this literature is that the impact of geographic characteristics on locational choice is anything but neutral. For example, the collection of European country studies included in the special issue of Regional Studies, on "Regional Variations in New Firm Formation” (Reynolds, Storey and Westhead, 1994), identified a number of geographic specific characteristics that impact the location of new firms. These characteristics were generally based on those factors identified in earlier studies by Carlton (1983) and Bartik (1985).

However, none of these studies focused on the role of accessing knowledge spillovers in the locational choice decision of new firms. This oversight is surprising, given that the growing literature on technology management and the economics of innovation has found that knowledge spillovers play an important role in fostering entrepreneurship and innovative activity (Sorenson and Audia, 2000; Baum and Sorenson, 2003). In addition, spillovers from universities, as well as from private firms, have been identified as a key source promoting firm innovation and performance (Stuart and Sorenson, 2003). 
The purpose of this paper is to address these significant holes in the literature linking locational choice as a strategic firm decision to knowledge externalities in general and spillovers from universities in special. We do this by linking the locational choice of firms in terms of proximity to a university to both the type of knowledge produced at universities as well as the actual spillover mechanism transmitting that knowledge. In particular, the importance of locational proximity to a university is analyzed in terms of two distinct types of knowledge and two distinct spillover mechanisms in order to identify whether the role of geographic proximity to a knowledge source is heterogeneous with respect to the type of knowledge as well as the actual spillover mechanism.

In the second section we explain how and why locational proximity to a university should accrue benefits to knowledge based startups. In section three, the different types of knowledge outputs and different mechanisms used by firms to access knowledge spillovers from universities are discussed. Not only are the types of knowledge and spillover mechanisms heterogeneous, but the capacity to generate knowledge spillovers also varies considerably across universities. Thus, in section four a new data base consisting of 281 publicly listed firms in German high technology and knowledge industries is used to identify empirically in section five how locational choice varies for different types of knowledge and spillover mechanisms. In the last section a summary and conclusion are provided. In particular, the evidence suggests that, in general, new knowledge and technological-based firms have a high propensity to locate close to universities, presumably in order to access knowledge spillovers. However, the exact role that geographic proximity plays is shaped by the two factors examined in this paper -- the particular knowledge context, and the specific type of spillover mechanism. 


\section{Geographic Proximity to Universities as a Locational Strategy}

There are two strands of literature linking locational choice as a strategic decision to access and absorb knowledge spillovers. The first strand in the literature focuses on the existence and geographic distribution of university spillovers. The second set of studies deals with the impact of location on the entrepreneurial choice to start and sustain a new firm. While the first strand of literature establishes that knowledge not only spills over from universities but is also spatially bounded, an implication for the model of entrepreneurial choice is that the prospects for a new firm are greater in locations conducive to accessing and absorbing those knowledge spillovers. Thus, the major premise of the location argument is that new firms would like to reduce their knowledge acquisition costs by locating close to the knowledge source, the university. However, those benefits must bear the higher costs of locational proximity to a university.

The prevalent theoretical framework analyzing the decision to start a firm has been the general model of entrepreneurial choice. The model of entrepreneurial choice dates back at least to Knight (1921), but was more recently extended and updated by Kihlstrom and Laffont (1979), Holmes and Schmitz (1990), Jovanovic (1994), Lazear (2002), Alvarez and Barney (2003) among others. None of the above models or studies considers the role of location in the context of the entrepreneurial choice framework. However, geographic location should influence the entrepreneurial decision by altering the expected return from entrepreneurial activity. 
The theory of localized knowledge spillovers suggests that profits will tend to be greater in agglomerations and spatial clusters, since access to tacit knowledge is greater. Because firms access external knowledge at a cost that is lower than the cost of producing this value internally or of acquiring it externally from a geographic distance (Harhoff, 2000), they will exhibit higher expected profits. The cost of transferring such knowledge is a function of geographic distance and gives rise to localized externalities (Siegel et al. 2003). Thus, the empirical analysis of university spillovers assumes that the geographical dimension is a key factor explaining the innovative activities of firms.

University spillovers could be defined by externalities towards firms, for which the university is the source of the spillover but is not fully compensated (Harris, 2001). Some models of assume that geography plays no role in the cost of accessing that knowledge (Spence, 1984; Cohen and Levinthal, 1990). However, theories of localization suggest that just because knowledge spills over from universities does not mean that it transmits costless across geographic space. In particular, these theories argue that geographic proximity reduces the cost of accessing and absorbing knowledge spillovers. Thus, a basic tenet in the literature is that university spillovers lower the costs of firms to accessing and absorbing knowledge spillovers. If an entrepreneur decides to locate closely towards a universities, the benefits must outweigh the costs. Locating close to universities, mostly in the center of a city, is associated with high costs of living, housing, and others. Though, firms also have to pay higher wages to their employees since their costs of living but also their opportunity costs are higher in the large university cities. If the basic resources gathered from a university are not essential to bear those costs, it is more advantageous to locate outside such a metropolitan area. 
There are both theoretical reasons and empirical evidence to believe that such knowledge spillovers generated by universities are not accessed and absorbed at costs that are invariant to geographic location (Bottazzi and Peri, 2003). Rather, because university spillovers tend to be spatially bounded, the cost of absorbing them increases along with the locational distance from the university. An implication of the geographic distribution of knowledge spillovers is not only that they are spatially clustered around universities, but that the entrepreneurial opportunities to start a new firm are also geographically linked to the spatial distribution of knowledge spillovers. The limited geographic reach of such channels for the exchange of information and know-how is one of the leading causes of the impact of geographical proximity. Or, with the words of Alfred Marshall (1890) more than a century ago, "the mysteries of the industry are in the air". Thus, the benefits of locating close towards a university disappear with distance. Thus, a key hypothesis of this paper is that the value of locating within close geographic proximity to a university will depend upon the university output. In particular, the locational strategy of firm geographic proximity to a university should be more important when the knowledge output of the university is high.

\section{Spillover Mechanisms - Research \& Human Capital}

There are at least two main mechanisms facilitating the spillover of knowledge from universities to firms. The first one involves scientific research published in scholarly journals. Such published research can be considered to constitute codified knowledge. This is because knowledge provided by articles can be transferred and transmitted with very low costs, or with costs which are independent from the location. Academic papers 
can be downloaded by the internet or from publishers. The prices for downloads or postal services, however, are rather independent from the location which produced this kind of knowledge or information. This suggests that an important testable hypothesis is that the amount of scientific articles published by a university has no effect on firm location, since accessing (codified) knowledge is invariant to locational distance from the university producing that knowledge.

However, an important qualification is that not all university knowledge is the same. In fact, the knowledge output of a university is heterogeneous. One useful distinction differentiates knowledge in the natural sciences from that in the social sciences. Social science knowledge is not based on a unified and established scientific methodology, but it rather is idiosyncratic to very specific disciplines, sub-disciplines and even research approaches. Compared to the natural sciences, research in the social sciences is considerably less codified. Thus, geographic proximity to high output universities may be more important for accessing social science research than for accessing natural science research.

The second type of spillover mechanism involves human capital embodied in students graduating from the university. As Saxenien (1994) points out, one of the important mechanisms facilitating knowledge spillovers involves the mobility of human capital, embodied in graduating students, as they move from the university to a firm. Spatial proximity to universities can therefore generate positive externalities that can be accessed by the firm through the spillover mechanism of human capital. As Varga (2000) shows, university graduates may be one of the most important channels for disseminating knowledge from academia to the local high technology industry. In 
addition, other related externalities may result from close geographic proximity. For example, local proximity lowers the search costs for both firms and students. This may lead to some competitive advantage over similar firms which are not located close to universities, especially when high skilled labor is a scarce resource and there is intense competition about high potentials. ${ }^{1}$

Central to the theories of localized knowledge spillovers is the distinction between codified and tacit knowledge (Kogut and Zander, 1992). Tacit knowledge needs oral communication and reciprocity which may be ineffective or infeasible over longer distances. Such elements of know-how and operations cannot be codified easily in a blueprint or a contractual document (Mowery and Ziedonis, 2001). Thus, technology transfer or exchange is associated with personnel contacts. Such spillovers could be transmitted through certain conduits across geographic space such as the channels of communication, the social system, or a kind of technology diffusion process. Most of those benefits could not be obtained by markets or ensured by contractual arrangements. If personnel contacts are the main source for absorbing, the number of students of a university should have a positive impact on firm location. Thus, the relative importance of tacit knowledge is reflected by the number of students of a university, which serves as a measure for the intense demand for labor and interpersonal communication. Otherwise, the access to students also captures factors like network effects, social contacts and other sources of tacit knowledge. This suggests that the higher the human capital output of a university, the lower is the distance between a university and the firm. Apart from the spillover mechanism there might be at least two other groups of

\footnotetext{
${ }^{1}$ See also Stephan et al. (2002), analyzing the firm's placement of Ph.D. students.
} 
variables influencing the distance between a university and a new knowledge based firm: location variables and firm characteristics.

Previous research has found that the location of firms is affected by other location variables like the size of cities. It is possible that firms locate close to the areas where universities are located because of network reasons. One disadvantage of most studies on the impact of university spillover on firm location is to explain the negative sign of spillover sources. The only interpretation is, that those source - patents, citations, articles - are not essential to locate close towards a university. However, there is no rational argument for this "push away" effect as expressed by the negative sign. Since our basic assumption is that locating close towards a university is associated with high costs, we also include a measure for these costs. Now, the negative sign could be interpreted in the way that the trade-off between the costs and benefits of locating close to the universities is more influenced by the costs, i.e. the costs of the close location exceed the benefits of spillover effects.

As pointed out by Audretsch and Thurik (2001) among others, the impact of such spillovers may be more important for young firms than for established firms. This is because new firms may rely on external knowledge produced by either other firms or a university. It has been observed (Scherer, 1991) that small and new firms do not devote a large share of resources to formal R\&D. By contrast, larger and more established enterprises are able to generate their own formal $R \& D$, and therefore are less dependent upon external knowledge. This implies that geographic proximity to universities is a source of competitive advantage for young firms, when the competitive advantage is based on intangible assets, such as ideas and the human capital of the employees. This 
suggests that locational strategy of firm geographic proximity is more important for young firms. Finally, previous research has shown that spillover effects differ between industries in their necessity and capability to absorb spillover effects (Jaffe, 1989; Cohen and Levinthal, 1990; Henderson and Cockburn, 1994).

\section{$4 \quad$ Data and Methodology}

\subsection{The Data}

The link between geographical proximity and university spillovers is tested by using a unique dataset of all of knowledge and high technology German firms that were publicly listed on the Neuer Markt, Germany's counterpart of the NASDAQ. Between 1997 and 2002 the total number of firms listed in this index was 341. We excluded all firms located outside Germany as well as holding companies. Though, the underlying data set consists of 285 publicly listed German firms, collected from IPO prospectuses, and publicly available information from on-line data sources including the Deutsche Boerse AG www.deutsche-boerse.com. First, this database includes firms from highly innovative industries, like biotechnology, medical devices, life sciences, e-commerce and other high-technology industries which represent the knowledge-based economy. Secondly, there is strong evidence from the U.S. for a growth effect of clusters influenced by research active universities (Feldman 2000). Though, we are able to follow this line of research. Finally, this data set represents the technological change in the German business sector from the predominance of medium sized firms in the production and manufacturing towards the high-technology and service sector. 
The university related data is collected from different sources. Information about the number of students is provided by the Federal Statistical Office. Publication data are hand-collected from the research database ISI (Information Sciences Institutes).

As we examine the impact of university output on locational proximity to the university, the distance of a new knowledge based firm to the closest university is applied as endogenous variable (distance). This measure is sensible enough to ensure capturing also small differences in firm-university distances that is especially necessary in Germany as universities are much more geographically concentrated compared to the U.S. The online database of the German Automobile Club (www.adac.de) is used to determine the distance between the firm and the closest university. Firms located within a radius of 1.5 kilometers are classified as belonging in the distance category of 1 kilometer. Table 1 shows the descriptive statistics for the endogenous variable distance as well as for the exogenous variables. The median distance of a firm and a university is 7 kilometers while the mean is more than double as high with 16.75 kilometers. Thus, the variable distance is highly skewed. The $92 \%$ percentile shows of the endogenous variable is 50 kilometers and means that the $92 \%$ of the shortest distances from a firm to a university are 50 kilometers or even shorter. This quantile is chosen for several reasons. First, we assume that within this circle the firm is located in the metropolitan area of the university town. Second, we assume that this distance is the maximum distance for employees to travel each day from the inner-city to the respective firm. However, all the universities which are taken as the nearest university of those firms are universities located in big cities. 
The independent variables are categorized into three main groups. The first group contains spillover mechanism variables for research and human capital. The second group consists of location variables, which contain university location variables as well as firm location variables. And finally the third group considers firm specific variables.

To capture the first spillover mechanism research we include the number of articles published in high quality journals (see Zucker et al 1998; Audretsch and Stephan, 1996). Since university spillovers are not restricted to patented inventions ${ }^{2}$ and occur not solely in the natural sciences, we include measures for social science research output as well as natural science output. This enables us also to discriminate between the types of spillover effects. Since knowledge-based industries include services such as media and entertainment, service, or e-commerce, spillovers can also be generated by fields without high patent activities. Research in the social sciences is captured by the number of articles published in journals listed in the Social Science Citation Index (SSCI). The number of publications in the Science Citation Index (SCI) indicates the research activity of universities in the natural sciences. We includ the number of listed papers of both indices for each university published from 1997 until 2000. ${ }^{3}$ Table 1 clearly shows that the universities differ in their research activities, both in natural sciences and social sciences. Of course, the number of articles in natural sciences cannot be compared to those in social sciences as articles in natural science are mostly shorter papers, written by a number of co-authors. However, the median university published in this time period 204 articles in the social sciences and 4,069 in the natural

\footnotetext{
${ }^{2}$ For an analysis of university patenting see Henderson et al (1998) and Jaffe et al (1993). For university patenting see Jensen and Thursby (2001) and Jensen et al (2003).

${ }^{3}$ The publications in social science and natural science did not vary across the universities during time.
} 
sciences. In both fields the mean value exceeds the median value which clearly predicts that some universities are more research intense than others.

The second spillover mechanism "human capital" is captured by the number of students enrolled at a university. In analogy to the research mechanism we consider students from the natural sciences and from the social sciences separately to control for the different types of spillover. We calculated the number of students in natural sciences and social sciences by adding the number of students from different disciplines. The natural sciences students' variable contains the study fields biology, chemistry, physics, mathematics, computing, agriculture, forestry, dietetics, engineering, and medicine. The social science variable consists of students from the fields of languages, cultural studies, law, economics, social science, and arts. For two reasons, all student data are taken from the year 1997. First, those data are not always available for every year and university. Second, the Neuer Markt started in 1997 and thus we take this year as the basic year. As shown in table 1, the number of fresh graduates in the social sciences doubles those in natural sciences.

The second group of exogenous variables consists of location variables for the university as well as for the firm. The number of inhabitants form the location of the university is taken from the official statistics based on 1997 as proxy for the size of the town where the university is located. In the lack of adequate data for the costs of living at the university location we include the average price of a single room - no suite or presidential room etc. - from the most expensive hotel in the city where the university is located. Those prices differ significantly across cities with the most expensive in Frankfurt - which is also the most expensive city in Germany as measured by the 
OECD. The number of universities in the town captures a cluster effect but also a competition effect between the universities. The variables of firm location include the number of inhabitants in the location of the firm and a dummy variable that indicates location of the firm in the former Western part of Germany.

In the third group of exogenous variables we control for specific industry effects, by including dummy variables for the following industries: Software, E-Services, ECommerce, Computer \& Hardware, Telecommunication, Biotechnology, Medicine \& Life science, Media \& Entertainment, and High-Technology. Furthermore, the age of the firm is considered as special characteristic.

\subsection{Analysis and Methodology}

A closer look on table 1 shows that the data are highly skewed so that OLS-method is not appropriate to test the hypotheses. Thus we decide to use the method of quantile regressions to test our hypotheses. This semi-parametric technique provides a general class of models in which the conditional quantiles have a linear form. In its simplest form, the least absolute deviation estimator fits medians to a linear function of covariates. The method of quantile regression is potentially attractive for the same reason that the median or other quantiles are e better measure of location than the mean. Other useful features are the robustness against outliers and that the likelihood estimators are in general more efficient than least square estimators. Besides the technical features, quantile regressions allow that potentially different solutions at distinct quantiles may be interpreted as differences in the response of the dependent variable, namely the distance, to changes in the regressors at various points in the 
conditional distinction of the dependent variable. Thus, quantile regressions reveal asymmetries in the data, which could not be detected by simple OLS estimations (see Buchinsky 1998). While the median regression focuses on the median firm, the regression on the 92\%-quantile focuses on the firms 50 kilometers away from the university.

\section{$5 \quad$ Empirical Results: Startup Proximity to a University}

In order to identify the impact of university output on the importance of locational proximity to the university, table 2 shows the median regression and the $92 \%$-quantile regression results. Using these two different estimates enables us to examine the impact of startups with greater distance from the university (compared to the median). As the positive and statistically significant coefficient of the number of publications in the natural sciences suggests, new firms do not have a high propensity to locate within close proximity to universities with a high research output in the natural sciences. In fact, as the research output increases, the distance of the new startup from the university also tends to increase. Thus, there is no statistical evidence suggesting that new firms locate close to research universities in order to access the spillover of knowledge using the research mechanism for they knowledge type represented by the natural sciences.

However, as the negative and statistically significant coefficient of the number of publications in the social sciences indicates, the importance of locating within close geographic proximity to a university may not be invariant to the type of knowledge. This result suggests that knowledge transmitted through published research in the social sciences may, in fact, be less codified and more tacit, leading new firms to locate closer 
to the university in order to access the knowledge spillover.

The results in table 2 in the first column also suggest that the magnitude of university output in the form of human capital also affects locational decisions. As the negative and statistically significant coefficient of the number of students in the natural sciences indicates, new firms tend to locate more closely to universities with a larger output of students. However, this result does not hold in the social sciences. This may indicate that human capital in the natural sciences is more specific and less general than in the social sciences. The results also indicate that the other location specific characteristics also impact the locational choice of new firms. The size of the city in which the university is located, the cost of living in which the university is located, and the city size where the firm is located are all found to influence the locational decision of new firms. As column two in table 2 shows, the results are considerably different when the 92.5 percent quantile estimation is used. Neither the spillover mechanisms nor the knowledge types have a statistically significant impact on the location of new firms. This would suggest that the knowledge spillovers are geographically bounded within 50 kilometers from the university.

\section{$6 \quad$ Conclusions}

A recent literature has emerged suggesting that regional characteristics have an important impact on the locational decisions made by new firms. The findings of this paper reinforce this literature, but identify an additional locational factor as the presence of a university. New firm startups, at least in the knowledge and high technology 
sectors, are influenced not only by the traditional regional characteristics, but also by the opportunity to access knowledge generated by universities.

An important finding of this paper, however, is the impact of university output on new firm location is sensitive to both the type of knowledge and mechanism used to access that knowledge. Thus, the role of geographic proximity to access university knowledge is not simple and straightforward, but rather depends on the knowledge type and spillover mechanism.

Future research may be expected to focus less on uncovering the existence of knowledge spillovers from universities and more on identifying the heterogeneity inherent in both types of knowledge generated by universities as well as the various mechanisms by which knowledge spillovers from universities are accessed by firms. 


\section{References}

Alvarez, S.A. and J.B. Barney 2003. Organizing Rent Generation and Appropriation: Toward a Theory of The Entrepreneurial Firm. Journal of Business Venturing (forthcoming).

Audretsch, D.B. and P.E. Stephan 1996. Company-Scientist Locational Links: The Case of Biotechnology, American Economic Review, 86, 641-652.

Audretsch, D.B. and R. Thurik, 2001. What's New about the New Economy? Sources of Growth in the Managed and Entrepreneurial Economies, Industrial and Corporate Change, 10, 267-315.

Bartik, T.J., 1985. Business Location Decisions in the United States: Estimates of the Effects of Unionization, Taxes, and other Characteristics of States, Journal of Business and Economic Statistics, 3, 14-22.

Baum, J.A.C. and O. Sorenson, 2003. Advances in Strategic Management: Geography and Strategy, Vol. 20, JAI Press: Greenwich CT (forthcoming).

Bottazzi, L. and G. Peri, 2003. Innovation and spillovers in regions: Evidence from European patent data, European Economic Review 47, 687-710.

Buchinsky, M., 1998. Recent Advantages in Quantile Regression Models, Journal of Human Resources, 33, 88-126.

Carlton, D.W., 1983. The Location and Employment Choices of New Firms: An Econometric Model with Discrete and Continuous Endogenous Variables, Review of Economics and Statistics, 54, 440-449.

Cohen, W.M. and D.A. Levinthal, 1990. Absorptive Capacity: A New Perspective on Learning and Innovation, Administrative Science Quarterly 35, 128-152. 
Feldman, M.P., 2000. Location and Innovation: The New Economic Geography of Innovation, in: Clark, G; Feldman, MP, and M. Gertler (Editors): Oxford Handbook of Economic Geography, Oxford University Press: Oxford.

Harhoff, D., 2000. R\&D Spillovers, Technological Proximity, and Productivity Growth - Evidence from German Panel Data, Schmalenbach Business Review 52, 238-260.

Harris, R.G., 2001. The Knowledge-Based Economy: Intellectual Origins and New Economic Perspectives, International Journal of Management Review 3, 2141.

Henderson, Rebecca, Adam Jaffe and Manuel Trajtenberg (1998): Universities as a Source of Commercial Technology: A Detailed Analysis of University Patenting 1965-1988, Review of Economics and Statistics 65, 119-127.

Henderson, R. and I. Cockburn, 1994. Measuring Competence? Exploring Firm Effects in Pharmaceutical Research, Strategic Management Journal 15 (special issue), 63-84.

Holmes, T.J. and J.A. Schmitz, 1990. A Theory of Entrepreneurship and its Application to the Study of Business Transfer, Journal of Political Economy 98, 265294.

Jaffe, A.B., 1989. Real Effects of Academic Research, American Economic Review 79, 957-970.

Jaffe, Adam B.; Manuel Trajtenberg and Rebecca Henderson (1993): Geographic Localization of Knowledge Spillovers as evidenced by Patent Citations, Quarterly Journal of Economics 63, 577-598. 
Jensen, R.A. and M. Thursby 2001. Proofs and Prototypes for Sale: The Licensing of University Inventions, American Economic Review, 91, 240-259.

Jensen, R.A., Thursby, J.G. and M.C. Thursby 2003. Disclosure and Licensing of University Inventions: 'The Best We Can Do with the S**t We Get to Work With', International Journal of Industrial Organization, 21, 1271-1300.

Jovanovic, B., 1994. Entrepreneurial Choice When People Differ in their Management and Labor Skills, Small Business Economics 6 (3), 185-192.

Khilstrom, R. and J.-J. Laffont, 1979. A General Equilibrium Entrepreneurial Theory of Firm Formation Based on Risk Aversion, Journal of Political Economy 87, 719-748.

Krugman, P., 1991. Geography and Trade, Leuven University, MIT Press.

Knight, F., 1921. Risk, Uncertainty and Profit, Augustus Kelly:New York.

Kogut, B. and U. Zander, 1992. Knowledge of the Firm, Combinative Capabilities, and the Replication of Technology, Organizational Science 3, 383-397.

Lazear, E.P., 2002. Entrepreneurship, NBER working paper No. 9109.

Marshall, A., 1890, Principles of Economics, London: MacMillan.

Mowery, D.C. and A. A. Ziedonis (2001): The Geographic Reach of market and NonMarket Channels of Technology Transfer: Comparing Citations and Licenses of University Patents, NBER working paper No. 8568.

Reynolds, P.D., Storey, D.J. and P. Westhead (1994): Regional Variations in New Firm Formation - Special Issue, Regional Studies, 28, 343-456.

Saxenian, A., 1994. Regional Advantage: Culture and Competition in Silicon Valley and Rte. 128, Cambridge/Mass: Harvard University Press. 
Scherer, F.M. 1991. Changing Perspectives on the Firm Size Problem, in: Acs, Z.J. and D.B. Audretsch (editors), Innovation and Technological Change: An International Comparison (University of Michigan Press, Ann Arbor), 2438.

Siegel, D.S., Westhead, P., and M. Wright, 2003. Assessing the Impact of Science Parls on the Research Productivity of Firms: Exploratory Evidence from the United Kingdom, International Journal of Industrial Organization (forthcoming).

Sorenson, O. and G. Audia, 2000. The Social Structure of Entrepreneurial Activity: Geographic Concentration of Footwear Production in the U.S, 1940-1989, American Journal of Sociology 106, 324-362.

Spence, M.A., 1984. Cost Reduction, Competition, and Industry Performance, Econometrica 52, 101-121.

Stephan, P.E., Sumell, A.J., Black, G.C., and J.D. Adams, 2002. Public Knowledge, Private Placements: New Ph.D.s as a Source of Knowledge Spillovers, Economic Development Quarterly (forthcoming).

Stuart, T. E. and O. Sorenson, 2003. The Geography of Opportunity: Spatial Heterogeneity in Founding Rates and the Performance of Biotechnology Firms, Research Policy (forthcoming).

Varga, A., 2000. Local Academic Knowledge Transfers and the Concentration of Economic Activity, Journal of Regional Science 40, 289-309.

Zucker, L. G., Darby, M. R., and J. Armstrong, 1998. Intellectual Human Capital and the Birth of U.S. Biotechnology Enterprises, American Economic Review 88, 290-306. 
Table 1: Descriptive Statistics

\begin{tabular}{lccccc}
\hline & Mean & Std. Dev. & Min & Max & Median \\
\hline Distance & 16.75 & 23.93 & 1 & 177 & 7 \\
No of Publications in Natural Sciences & $5,139.43$ & $4,603.16$ & 0 & 14,176 & 4,069 \\
No of publications in Social Sciences & 253.86 & 220.01 & 0 & 659 & 204 \\
No of students in Natural Sciences & $7,304.89$ & $3,988.45$ & 0 & 20,570 & 7,725 \\
No of students in Social Sciences & 20,321 & $15,409.63$ & 0 & 47,112 & 15,741 \\
Inhabitants of the city of the university & 916,796 & 830,554 & 498,000 & $3,410,000$ & 615,000 \\
Hotel price in the university town in Euro & 180.81 & 68.44 & 55 & 319 & 179 \\
No of universities in the city & 1.84 & 0.960 & 1 & 3 & 1 \\
Inhabitants of firm location & 640,442 & 897,371 & 1850 & $3,387,000$ & 190,000 \\
Firm age & 10.400 & 10.025 & 0.1 & 90 & 8 \\
\hline
\end{tabular}




\section{Table 2: Quantile Regressions on the Median and the 92\%-Quantile}

The endogenous variable is the distance from the new firm to the closest university. t-values are in brackets. The baseline is firms in the technology sector. The asterisks, *,**, and *** indicate significance at the 10-percent, 5-percent, and 1-percent level, respectively. The number of observations is 281.

\begin{tabular}{|c|c|c|c|}
\hline & & Median & 92\%-Quantile \\
\hline \multicolumn{4}{|c|}{ Spillover mechanism Research } \\
\hline & Natural Science Research & $0.0012(3.22)^{* * *}$ & $-0.0016(0.26)$ \\
\hline & Social Science Research & $-0.0303(3.80)^{* * *}$ & $0.1116(0.69)$ \\
\hline \multicolumn{4}{|c|}{ Spillover mechanism Human Capital } \\
\hline & Natural Science Human Capital & $-0.0005(4.93)^{* * *}$ & $-0.0002(0.10)$ \\
\hline & Social Science Human Capital & $0.0001(2.31)^{* *}$ & $-0.0011(0.88)$ \\
\hline \multicolumn{4}{|c|}{ Location variables } \\
\hline & City Size [for university] & $0.0153(11.01)^{* * *}$ & $0.0323(1.45)$ \\
\hline & Cost of Living [university] & $-0.0258(3.58)^{* * *}$ & $-0.0895(0.56)$ \\
\hline & Number of universities in town & $-2.0271(2.16)^{* *}$ & $-13.822(0.82)$ \\
\hline & West Location & $3.8011(2.31)^{* *}$ & $-12.180(0.91)$ \\
\hline & City Size [for firm] & $-0.0134(15.71)^{* * *}$ & $-0.0365(2.58)^{* * *}$ \\
\hline \multicolumn{4}{|c|}{ Firm characteristics } \\
\hline & Firm Age & $0.0507(1.37)$ & $-0.3421(0.64)$ \\
\hline & Software & $0.4966(1.26)$ & $-0.3421(0.11)$ \\
\hline & Service & $-1.1929(1.16)$ & $9.7641(0.45)$ \\
\hline & E-commerce & $1.8528(1.16)$ & $35.874(1.12)$ \\
\hline & Hardware & $-1.1422(0.80)$ & $22.321(0.85)$ \\
\hline & Telecom & $0.7564(0.50)$ & $-4.315(0.25)$ \\
\hline & Biotechnology & $-5.0633(3.13)^{* * *}$ & $-4.4202(0.12)$ \\
\hline & Medical Devices & $-1.0453(0.55)$ & $2.8956(0.15)$ \\
\hline & Media & $-4.0047(3.24)^{* * *}$ & $-5.9651(0.25)$ \\
\hline Constant & & $11.9244(6.05)^{* * *}$ & $96.441(3.33)$ \\
\hline Pseudo R2 & & 0.1603 & 0.2848 \\
\hline
\end{tabular}

The variables for City Size [for university] and City Size [for firm] are multiplied with 1,000. 